\title{
Motivation of Volunteering Activities among University Students
}

Nur Hani Syazwani Bakri, Azman Ahmad Tajri, Mohd Firdaus Ahmad, Nur Dalilah Dahlan, Siti Aida Lamat

To Link this Article: http://dx.doi.org/10.6007/IJARBSS/v11-i11/11302

DOI:10.6007/IJARBSS/v11-i11/11302

Received: 11 September 2021, Revised: 28 September 2021, Accepted: 20 October 2021

Published Online: 09 November 2021

In-Text Citation: (Bakri et al., 2021)

To Cite this Article: Bakri, N. H. S., Tajri, A. A., Ahmad, M. F., Dahlan, N. D., \& Lamat, S. A. (2021). Motivation of Volunteering Activities among University Students. International Journal of Academic Research in Business and Social Sciences, 11(11), 764-770.

Copyright: (c) 2021 The Author(s)

Published by Human Resource Management Academic Research Society (www.hrmars.com) This article is published under the Creative Commons Attribution (CC BY 4.0) license. Anyone may reproduce, distribute, translate and create derivative works of this article (for both commercial and non-commercial purposes), subject to full attribution to the original publication and authors. The full terms of this license may be seen at: http://creativecommons.org/licences/by/4.0/legalcode

Vol. 11, No. 11, 2021, Pg. $764-770$

Full Terms \& Conditions of access and use can be found at http://hrmars.com/index.php/pages/detail/publication-ethics 


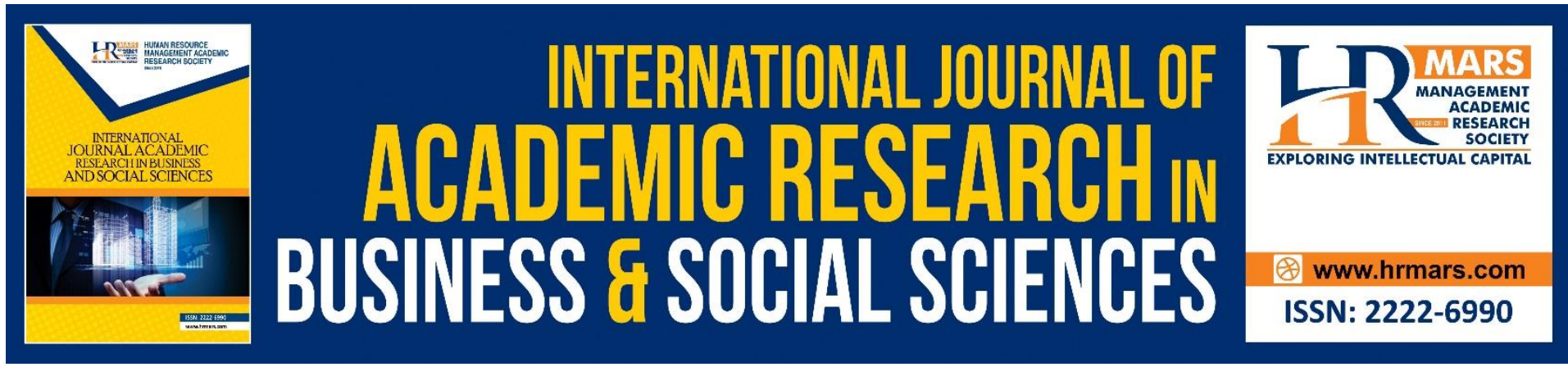

\title{
Motivation of Volunteering Activities among University Students
}

\author{
Nur Hani Syazwani Bakri, Azman Ahmad Tajri, Mohd Firdaus \\ Ahmad, Nur Dalilah Dahlan, Siti Aida Lamat
}

Faculty of Sport Science and Recreation, Universiti Teknologi Mara (UiTM), Cawangan

Negeri Sembilan, Kampus Seremban

Email: hanisyazwani@uitm.edu.my

\begin{abstract}
Volunteering activity (VA) are important key as a bridge between a person, group of people, organisation to community as a function of social activity. It is an activity that encourage this group to give more and as return they would get benefits includes their purpose of involving volunteering, socials, supportive, leisure and most important helps in their career. Researchers tend to look at the motivation factor contributing to VA among university students. The samples are from 327 students who voluntary participated in this study. There is significance difference in term of "purposive" ( $p=.047<0.05)$, "career" $(p=.001<0.05)$, "leisure" ( $p=.003<0.05)$, "social" ( $p=.001<0.05)$ and "supportive" ( $p=.019<0.05)$. In addition, when it shown women student more participate in VA compared to male with mean are higher. Study found that tertiary students are motivate when VA has purposive, supportive, social, leisure and at the same time it would help them in build their career after study.
\end{abstract}

Keywords: University Students, Motivation, Volunteering Activities.

\section{Introduction}

Volunteerism is an activity volunteering by individual, group of people, organisation contributing to community Faranadia et al (2018). This activity can be joining by vary of age and social status. This activity is not drive by monetary, but it benefited to themselves especially in self-development. In addition, the most important reason to participate in this volunteering activity are to help community itself, to learn new skills, to respond to the skills, helps gain experiences and for future career. Younger volunteers are important group to continue this legacy in future. Yet, this activity still needs to be expose in younger people especially among tertiary students. To encourage student to participate in this activity, they need to have some knowledge about the function of doing VA. Thus, it is advisable to university to involve student in organise some event that related to voluntary activity.

Mostly university in Malaysia has offered programmed and course that would involving students with the community throughout their assessment as a weightage of marks for the 
student grade. All over, this kind of activity could help tertiary student in build their social and interpersonal skills that can be applied after study. Align with this, surely involving with VA would advantage for future career (Holdsworth, 2010).

Although this VA recognised as one the meaningful for social development, regrettably to share there are still tertiary student are not participating in. A survey done by Australian university showed that $42.1 \%$ of student recently involved with VA compared to 74.4 . had volunteered in the past (McCabe et al., 2007). Finding from Kim et al (2010), stated the number of volunteers is drop significantly during 2010. Identically, in Malaysia VA still need a further study (Turiman et al., 2009). Continuing to address this issue, Hassan et al (2010) stated, that the percentage of tertiary student involving in volunteering activity are considered low. This is supports by Julinawati et al (2012), found that the spirit of volunteerism among student are still in moderate.

Apparently, there is a reason why this VA are not participating by tertiary students. Lacking in motivation could be one of factor that attribute to the problems. Supported by Abdul Latif, A. et al., (2012), stated, students are not involving in VA because of the program offered did not meet the needs of the students and it affect to the student's motivation. Since they are tertiary students and been expose to the university environment, they tend to be more selective in picking activity including type of activities, benefits and short- and long-term commitment (Rehberg, 2005). Therefore, it is important to identify which motivation factor influencing the tertiary student involving in volunteering activity.

\section{Literature Review}

\section{The Factor of Influencing Motivations}

It essential to begin with knowing motivation factors influencing the VA among tertiary students. Motivation is a start-up of any change of action. By aiming the objective, it would drive an individual toward it. Same thing applied when it is involving in VA. Tertiary student would involve in activity that would help them in the future especially in career. This motivation can be explained as below:

Purposive motivation can be explained by a desire to do something meaningful and contribute to the community. Burns et al (2008) stated, female students involving in VA because of the feel of caring as though they are doing something compared to men who volunteer for extrinsic factor. This finding also found that, there is generally differences between gender in motivation.

In supportive motivation, through joining this activity, it would help to gaining new perspective, feeling important and feel needed. Comparing to gender, female volunteer is significantly more empathetic than males (Jr \& Samu, 2002). Volunteerism women are challenging their traditional place in society and experiencing greater empowerment.

As for social motivation, it can be described as collection of people that are interact to each other by having a common characteristic and interest. At the level of individual as a volunteer, it would help an individual to overcome feelings of personal isolation and start to break the wall. Since volunteering activity require face to face, indirectly helps in self-belonging and contributing (Smith et al., 2004). In term of gender, Barbu et al (2011), found that girls are 
having a complex social and linguistic development stages earlier than a male. This has allowed them to form easy relationship based on operative play and share conversation.

Leisure in volunteering can be group as a serious leisure but sometimes it can be casual. Volunteering as leisure, individual would understand motivation drive volunteering and would examine the value of volunteer contribution. Study done by Badelt \& Hollerweger, (2001), found male more interested in volunteering that related to culture, entertainment and sport as compared to women more to social services. Moreover, gender differences make differences in perception where women are more to have an empathy rather than male.

In term of career motivation, it is important to explore and experience this VA to build a good career. By involving this activity, it would help an individual gain experience and career contact Bang \& Chelladurai, (2003). Based on finding by Burns et al. (2008), contrast to male students, women student has a strongly motivated to enhance and enrich their personal development, negative feeling and willing to practice new skills.

\section{Methodology}

The objective of this study aims to examine motivation factor that influencing in volunteering among university students and to identify the differences motivation in term of gender. A set of questionnaires were used in this study and been distributed through online platform. It involves 327 students as a sample. For data collection, questionnaire with 5 Likert- type scale is used and there are five (5) factors distinguish motivation and influence tertiary students in VA. The data was analysed by using Statistical Package for Social Science (SPSS) 26. Descriptive analyses were used to determine the mean each factor and independent $t$-test were to answer question about motivation differences influencing in VA in term of gender.

\section{Results}

Table 1 shows the motivation factor that led to involving tertiary student in VA. The result of the analysis shows the purposive factor (2.4) be a highest factor why tertiary student involve in VA. However, the most student shows the supportive factor (2.27) be the lowest mean of motivation factor.

Table 1: Results of Mean value of motivation factor

\begin{tabular}{|l|l|l|}
\hline & Mean & Std. Deviation \\
\hline Purposive & 2.4 & 1.27494 \\
\hline Career & 2.37 & 1.27494 \\
\hline Leisure & 2.33 & 1.27494 \\
\hline Social & 2.3 & 1.18585 \\
\hline supportive & 2.27 & 1.21768 \\
\hline
\end{tabular}

Next, Table 2 shows the results of differences motivation influencing VA in term of gender. It indicates there is significant differences between gender in all motivation factor where mean female for every motivation are higher compared to male tertiary students. 
Table 2: Results of differences between gender in motivation factor

\begin{tabular}{llllll}
\hline Variables & & Mean & t-value & df & p-value \\
\hline Purposive & Male & 2.1287 & -4.096 & 306.472 & .047 \\
& Female & 2.6971 & & & \\
Career & Male & 2.1053 & -4.034 & 286.708 & .001 \\
& $\begin{array}{l}\text { Female } \\
\text { Leisure }\end{array}$ & 2.6554 & & & \\
& Male & 2.0175 & -4.923 & 301.815 & .003 \\
Social & Female & 2.6763 & & & \\
& Male & 2.024 & -4.085 & 278.729 & .001 \\
& Female & 2.5737 & & & \\
Supportive & Male & 2.0195 & -4.012 & 310.131 & .019 \\
& Female & 2.5513 & & & \\
\hline
\end{tabular}

\section{Discussion}

This present study shows that purposive factor be a main factor why tertiary student are involving in VA. These scenarios happened because of tertiary student know the purpose of VA and it can influence in their lifestyle after study. It supported by Rehberg (2005), stated student tend to be more selective in choosing their activity, benefits, and commitment. Some other research also found that men are more likely to engage in sport and recreation volunteering compared to women are drive by volunteering in human services, religious as well as in educational organization (Einolf, 2010). Therefore, it is important to university to organize an event involving community, where student can contribute and experience, as indirectly it helps their soft skills that can be applied after study.

On the other hand, in millennium era, the involvement in both gender in VA is highly needed to ensure that communities are been serve well. Different gender will contribute to different view in VA. The finding of this study about motivation factor in different gender found that female student is more motivated in every motivation factor compared to men. This can be supported by study done by Rokach \& Wanklyn (2009), majority of the volunteer work is composed of women and highly educated. In addition, in several studies concerning gender differences in volunteer motivation, researchers have found that women score higher on most, if not all, functions than men (Chapman \& Morley, 1999; Fletcher \& Major, 2004). Moreover, this study found all motivation factors contribute to the significant difference between gender. This supported by Wilson (2000), said gender differences will shows differences level of empathy but the main objective is they concerned to help another person even though they're not related. But contrast to the other finding, said that social and career are significant differences between gender ( $H$ \& A, 2011). By looking at results, tertiary student is group that can give a huge impact on society. Overall, despite of the differences between gender in term of motivation factor, it can be concluded that it is good to have a program or event that organize by tertiary student especially in VA so that it can develop culture of volunteering. 


\section{Conclusion}

The finding obtained from this study are generalise the composition that equally distributed between gender where male (171) and female (156). Majority of students are undergraduate level. Results shows the highest mean among five motivation factor is purposive, follow by career, leisure, social and supportive. This study found that there are significant differences between motivation factor and gender involving VA. Through this finding it can be conclude that most of student are involving in VA and have the same rank in term of motivation factor and what makes them differences is only the differences between mean. Therefore, we can say that VA is extremely important among tertiary student, and it would help student after study in their communication skill, interpersonal skill and socializing with the communities surrounding them.

Although motivation is dependent on the demographic, it is crucial to stress motivation in tertiary student mainly in VA. The motive of motivation is varied, it depends on the individual itself on how they are driven by VA. Motivation is a predictor to predict personality. It concerns with person attitude and persuasion. Continuing, an individual engages in VA because it is purposeful activity and serve different psychological function. Some of individual might involve because egoistic motive and others due to altruistic motive or social motives.

With these studies, the evidence contributes to diverse implication. As this study focusing on tertiary student, this adds a piece of novel evidence, and it did not explore such differences in the volunteerism context since the sample itself are random sample. Some of limitation of study must be considered. For future studies, the researcher might look more into motivation, demographic and organization.

This line of study serves to inform about motivation and VA are important in educational lines and contribute to growth of tertiary student especially in their personality, mentally, physically and spiritually after study. As overall affected to their better performance of VA and other achievement.

\section{References}

Abdul Latif, A., Samsudin, A. R. L., \& P. \& Faizah, A. (2012). Understanding of environmental citizenship among Malaysian youths: A study on perception and participation. Asian Social Science, 8(5), 85-92.

Badelt, C., \& Hollerweger, H. (2001). Ehrenamtliche Arbeit in Non-Profit Sector. Structure and Management.

Bang, H., \& Chelladurai, P. (2003). No Title. Conference of the North American Society for Sport Management.

Barbu, S., Cabanes, G., \& LeManer-Idrissi, G. (2011). Boys and girlson the playground: Sex differences in social development are notstable across early development. PLoS ONE, 6,1

Burns, D. J., Reid, J., Toncar, M., \& Wells, C. A. C. (2008). he Effect of Gender on the Motivation of Members of Generation Y College Students to Volunteer. Journal of Nonprofit \& Public Sector Marketing, 19(1), 99-118.

Chapman, J., \& Morley, R. (1999). Collegiate service-learning. Journal of Prevention \& Intervention in the Community, 18(1), 19-33. 
Einolf, J. C. (2010). Gender Differences in the Correlate of Volunteering and Charitable Giving. Women's Philanthropy Institute at the Institute for Philanthropy at Indiana University and DePaul University School of Public Service.

Faranadia, A., Bukhari, W. M. Y., Kamal, M. Y., Normala, R., Lukman, Z. M., \& Azlini, C. (2018). Understanding and Assessing the Motivation Factors of University Students" Involvement in Volunteerism. International Journal of Research Innovation in Social Science (IJRISS), 2(12), 49-53.

Fletcher, T. D., \& Major, D. A. (2004). Medical students' motivations to volunteer: An examination of the nature of gender differences. Sex Roles, 51(1/2), 109-114

Hassan, A., \& Noordin, T. A., Sulaimana, S. (2010). The status on the level of environmental awareness in the concept of sustainable development amongst secondary school students. Procedia Social and Behavioral Sciences, 1276-1280.

Holdsworth, C., \& Quinn, J. (2010). Student Volunteering in English higher education. Studies in Higher Education, 35(1), 113-

Kim, M., Zhang, J. J., \& Connuaghton, D. (2010). Modification of the Volunteer Functions Inventory for Application in Youth Sports. Journal of Sport Management.

McCabe, T. L., White, K. M., \& Obst, P. L. (2007). The importance of volunteering functions to university students. Australian Journal of Volunteering, 12(2), 50-58.

Prentice, D. A., \& Carlsmith, K. M. (2000). Opinions and personality: On the psychological functions of attitudes and other valued possessions. In Why we evaluate functions of attitudes (pp. 223-248). Mahwah, NJ: Lawrence Erlbaum

Rehberg, W. (2005). Altruistic individualists: Motivations for international volunteering among young adults in Switzerland. Voluntas: International Journal of Voluntary and Nonprofit Organisations,16(2),109-122

Rokach, A., \& Wanklyn, S. (2009). Motivation to volunteer: Helping empower sick children. Psychology and Education: An Interdisciplinary Journal, 46(1), 7-25.

Smith, J. D., Ellis, A., Howlett, S., \& O’Brien, J. (2004). Volunteering for all? Exploring the link between volunteering and social exclusion. London, UK: Institute for Volunteering Research.

Switzer, C. L., Switzer, G. E., Stukas, A. A., \& Baker, C. E. (1999). Medical student motivations MOTIVATION BEHIND VOLUNTEERISM 36 to volunteer: Gender differences and comparisons to other volunteers. Journal of Prevention \& Intervention in the Community, 18(1-2), 53-64.

Turiman, S., Azimi, H., Ezhar, T., \& Ismi Arif, I., Muhammad Rezal, H., Siti Raba'ah, H., Dzuhailmi, D. (2009). Social networking among youth in Malaysia: The implication to nation building. Monograf IPSAS No 1. Serdang: Universiti Putra Press.

Widjaja, E. (2010). The motivation behind volunteerism. CMC Senior Theses

Wilson, J. (2000). Volunteering. Annual Review of Sociology, 26, 215-240 Wilson, J., and Musick, M. A. (2000). The Effects of Volunteering on the Volunteer. Law and Contemporary Problems, 62, 141-168. 